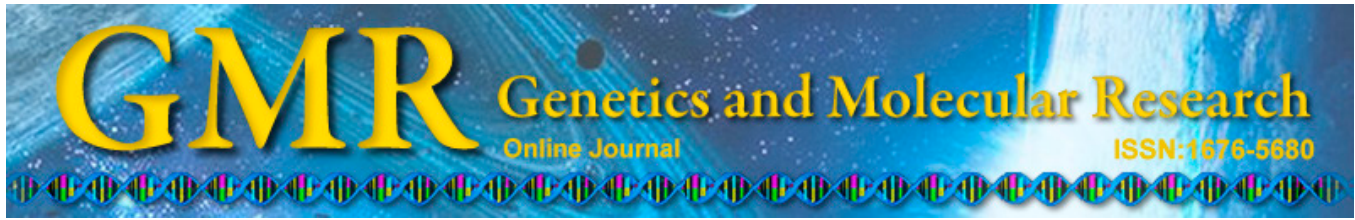

\title{
Polymorphisms and allele frequencies of glutathione $S$-transferases A1 and P1 genes in the Polish population
}

M. Skrzypczak-Zielinska ${ }^{1 *}$, O. Zakerska-Banaszak ${ }^{1,2,3 *}$, B. Tamowicz ${ }^{4}$, I. Sobieraj ${ }^{1}$, N. Drweska-Matelska ${ }^{3}$, M. Szalata ${ }^{1,3}$, R. Slomski ${ }^{1,3}$ and A. Mikstacki ${ }^{4}$

${ }^{1}$ Institute of Human Genetics, Polish Academy of Sciences, Strzeszynska, Poznan, Poland

${ }^{2}$ The NanoBioMedical Centre, Adam Mickiewicz University, Umultowska, Poznan, Poland

${ }^{3}$ Department of Biochemistry and Biotechnology, University of Life Sciences, Dojazd, Poznan, Poland

${ }^{4}$ Department of Anaesthesiology and Intensive Therapy, Regional Hospital, Juraszow, Poznan, Poland

*These authors contributed equally to this study.

Corresponding author: M. Skrzypczak-Zielinska

E-mail: mskrzypczakzielinska@gmail.com

Genet. Mol. Res. 14 (1): 2850-2859 (2015)

Received March 13, 2014

Accepted October 8, 2014

Published March 31, 2015

DOI http://dx.doi.org/10.4238/2015.March.31.15

ABSTRACT. Glutathione $S$-transferases (GST) A1 and P1 are crucial
enzymes involved in the biotransformation of drugs, carcinogens, and
toxins, and their activity may influence drug response, susceptibility
to diseases, and carcinogenesis. The genes encoding these enzymes,
GSTA1 and GSTP1, have been examined in many studies because of
their genetic variability, which may affect enzymatic activity. The goal
of this study was to determine the distribution of the alleles $G S T A 1 * A / * B$
and $G S T P 1 * A, * B$, and ${ }^{*} C$ in the Polish population. A total of 160
subjects from the Polish population were genotyped for 2 polymorphisms 
(I105V and A114V) in the GSTP1 gene using pyrosequencing. The promoter region of the GSTA1 gene was screened using sequencing. The detected variants were subjected to haplotype analysis. We found that the distribution of the alleles GSTA ${ }^{*} A /{ }^{*} B$ and $G S T P 1 * A, * B$, and ${ }^{*} C$ in the Polish population correspond to the results of studies in Caucasians. Furthermore, we identified additional single nucleotide polymorphisms, excluding 3 well-known changes (G-52A, C-69T, T-567G), which are linked to alleles $G S T A 1 * A / * B$, that affect enzyme activity. A total of 4 haplotypes were identified in 160 Polish individuals.

Key words: Genetic variants; GSTA1; GSTP1; Haplotypes

\section{INTRODUCTION}

The glutathione $S$-transferases (GSTs) are a superfamily of phase II metabolic enzymes that play a principal role in the metabolism and detoxification of carcinogens, environmental toxins, products of oxidative stress, and a broad range of drugs by catalyzing the conjugation between reduced glutathione and these electrophilic compounds (Hayes and Pulford, 1995). Currently, 8 soluble cytosolic classes of GST enzymes have been identified in mammals: $\alpha, \beta$, $\delta, \varepsilon, \theta, \mu, \pi$, and $\omega$. Each class shows specific substrate affinity and is encoded by 1 or several highly polymorphic genes located on different chromosomes (Oakley, 2005; Krajka-Kuźniak, 2007). Genetic variations in the genes coding for these xenobiotic-metabolizing enzymes can change the expression level of the protein product, thus influencing an individual's susceptibility to carcinogens and various diseases as well as affecting the toxicity and efficacy of some drugs. Therefore, they have been intensively studied (Hayes and Strange, 2000).

In this study, we examined 2 genes, GSTA1 and GSTP1, representing class $\alpha$ and class $\pi$, respectively, of the GST enzymes, whose polymorphisms have gained substantial attention recently. Class $\alpha$-GST is a dominant fraction of GST enzyme in the human liver, constituting $65-80 \%$ of the total amount, but this protein is also expressed in the kidneys, testes, adrenal glands, and small intestine. GST alpha 1 (GSTA1), the product of the GSTA1 gene, is essential in the formation of the hepatocyte homodimer GSTA1-1 (van Ommen et al., 1990; Rowe et al., 1997; Wu and Dong, 2012). The unique properties of this enzyme make it a more specific marker for hepatocellular impairment than the routinely used aminotransferases (aspartate and alanine aminotransferases) (Knapen et al., 2000). Therefore, this indicator has been widely analyzed for the hepatotoxic effect of different drugs such as anesthetics, nicardypine, and cimetidine, $N$-acetylcysteine (Ray et al., 1989a,b; Yousif et al., 2009; Beyaz et al., 2011).

Genetic polymorphisms in the GSTA1 gene, particularly in the promoter region, have been described: G-52A, C-69T, C-115T, A-513G, T-567G, G-631T, A-1066T, G-1142C, G1245A, and a silent substitution in exon 5 (A375G) (Coles et al., 2001; Tetlow et al., 2001). The promoter variants are characterized by 2 alleles GSTA1*A $(-52 \mathrm{G},-69 \mathrm{C},-567 \mathrm{~T})$ and $G S T A 1 * B$ (-52A, -69T, -567G), associated with differential hepatic expression (Coles et al., 2001). The nucleotide change at position -52 is known to prevent binding of the Sp1 transcription factor, reducing $G S T A 1 * B$ promoter activity by 4 -fold (Morel et al., 2002). However, the variant $-115 \mathrm{~A}$ decreases enzyme activity by 5 -fold (Coles et al., 2001). These alleles are strongly associated with the variable efficiency of metabolism and detoxification of numerous compounds, as well as drug therapy and susceptibility to diseases. For example, GSTA1 *B is asso- 
ciated with colorectal cancer because it causes inefficient detoxification of 2-amino-1-methyl6-phenylimidazo[4,5-b]-pyridine (Sweeney et al., 2002). In Caucasians, the GSTA ${ }^{*} B$ allele has been observed at a frequency of 38-50\% (Coles et al., 2001).

The GSTP1 gene, which codes for the GSTP1-1 protein of the $\pi$-GST fraction, is widely expressed in most tissues, particularly in the lung, esophagus, and placenta (Moscow et al., 1989). The variable expression level of $\pi$-GST has been used in multiple studies as an indicator of, for example, preeclampsia, lung and breast cancer, response to chemotherapy, drug hepatotoxicity, Parkinson disease, and pre-neoplastic tumors (Eger et al., 1997; Watson et al., 1998; Canto et al., 2008; Bai et al., 2012; Zhong et al., 2013). The polymorphic nature of the GSTP1 gene is responsible for the genetic variability of $\pi$-GST. Three polymorphic alleles of the GSTP 1 gene have been identified, including GSTP $1 * A, G S T P 1{ }^{*} B$, and $G S T P 1{ }^{*} C$. Allele GSTP $1 * A$ is characterized by isoleucine (Ile) at codon 105 and alanine (Ala) at codon 114, allele $* B$ is characterized by the substitution Ile $105 \mathrm{Val}$, while allele ${ }^{*} C$ is defined by 2 amino acid variations: Ile105Val and Ala114Val (Board et al., 1989). Both amino acid substitutions in codons $105($ c. $313 \mathrm{~A}>\mathrm{G})$ and $114($ c. $341 \mathrm{C}>\mathrm{T})$ are located in the active site of the GSTP1-1 protein and thus decrease the enzyme's catalytic activity by 4 -fold (Harries et al., 1997). In contrast, studies have shown that the Ile105Val substitution significantly reduced protein activity in the lungs in a Caucasian population (Watson et al., 1998).

Differences in the frequency of single nucleotide polymorphisms (SNPs) in the GSTA1 and GSTP1 genes between populations and ethnic groups have been reported (Harries et al., 1997; Watson et al., 1998; Tetlow et al., 2001; Morel et al., 2002).

The aim of our study was to identify polymorphisms, allele frequencies, and haplotypes in the GSTA1 and GSTP1 genes within a Polish population. There have been no previous studies examining the GSTA1 gene in the Polish population.

\section{MATERIAL AND METHODS}

\section{Human DNA samples}

In the present study, 160 healthy unrelated Polish individuals (89 males and $71 \mathrm{fe}-$ males) were examined. Genomic DNA of all subjects was obtained from peripheral blood according to standard procedures with guanidine isothiocyanate treatment. Blood samples were collected after obtaining written informed consent in collaboration with the Department of Anesthesiology and Intensive Therapy, Regional Hospital in Poznan, Poland. The study was approved by the Ethics Committee of the University of Medical Sciences in Poznan, Poland.

\section{Analysis of GSTP1 polymorphisms}

The GSTP1 gene is located on chromosome 11q13. Both polymorphisms, located at exon 5 at codon 105 and at exon 6 at codon 114, characterizing $G S T P 1 * A, G S T P 1 * B$, and $G S T P 1 * B$ alleles were analyzed using pyrosequencing, a rapid genotyping method. A set of specific primers for each substitution was designed using the Pyrosequencing PSQ Assay Design Software (Qiagen GmbH, Hilden, Germany). Primer sequences are shown in Table 1. Regions of interest containing substitutions were amplified by polymerase chain reaction (PCR) performed in $30-\mu \mathrm{L}$ reaction mixtures consisting of 96 ng DNA, 3.0 $\mu \mathrm{L}$ 10X PCR buffer, 2.4 $\mu \mathrm{L}$ dNTP mix (2.5 mM of each dNTP), $1.6 \mathrm{mM} \mathrm{MgCl}_{2}, 0.75 \mathrm{U}^{\text {FirePol }}{ }^{\mathbb{R}}$ DNA Polymerase, 
and $0.2 \mu \mathrm{M}$ specific primers. Amplification was carried out in a 2720 Thermal Cycler (Applied Biosystems, Foster City, CA, USA) with an initial denaturation for $95^{\circ} \mathrm{C}$ at 3 min and then 50 cycles as follows: $30 \mathrm{~s}$ at $95^{\circ} \mathrm{C}, 30 \mathrm{~s}$ at $60^{\circ} \mathrm{C}, 60 \mathrm{~s}$ at $72^{\circ} \mathrm{C}$, and a final elongation for 7 min at $72^{\circ} \mathrm{C}$. All PCR reagents were obtained from Solis BioDyne (Tartu, Estonia). The PCR products were analyzed by $2 \%$ agarose gel electrophoresis and then used as a template for pyrosequencing using the PSQ ${ }^{\mathrm{TM}}$ 96MA System (Qiagen) and Pyro-Mark ${ }^{\mathrm{TM}}$ Gold Q96 Reagents (Qiagen) as described by the manufacturer.

\begin{tabular}{|c|c|c|c|c|}
\hline Gene & Primer & Primer sequence $\left(5^{\prime}-3^{\prime}\right)$ & Primer location & Product size (bp) \\
\hline \multirow[t]{6}{*}{$\overline{G S T P 1}$} & $\mathrm{I} 105 \mathrm{~V}$ for & AATGACGGCGTGGAGGAC & Exon 5 & 75 \\
\hline & I105V_revBiot & CCTGGTGCAGATGCTCACATAG & & \\
\hline & I105V_seq & CTCCGCTGCAAATAC & & - \\
\hline & $\mathrm{A} 114 \mathrm{~V}_{-}$for & CTGGGAGGGATGAGAGTAGGA & Exon 6 & 107 \\
\hline & $\mathrm{A} 114 \mathrm{~V}$ revBiot & CAGGGTCTCAAAAGGCTTCAGT & & \\
\hline & $\mathrm{A} 114 \mathrm{~V}$ seq & GGTGTCTGGCAGGAG & & - \\
\hline \multirow{12}{*}{ GSTA1 } & A1 longF/fri for & ACCGTCCTGGCTCGACAA & Exon 1 & 1671 \\
\hline & $\mathrm{A} 1$ longR/fr $5 \mathrm{rev}$ & AAATGCCTATGACCAGATTTAGTT & Promoter & \\
\hline & A1_longF/fr1_for & ACCGTCCTGGCTCGACAA & Exon 1 & 366 \\
\hline & A1_fr1_rev & TCTCCCAGCTATGCTCACA & Promoter & \\
\hline & A1_fr2_for & TTTTCATGAGTTGGGTGCAA & Promoter & 387 \\
\hline & $\mathrm{A} 1_{-}^{-} \mathrm{fr} 2-\mathrm{rev}$ & TGCAATTGATGAATCCAGGT & Promoter & \\
\hline & $\mathrm{A} 1$ fr 3 for & ACCTGGATTCATCAATTGCA & Promoter & 363 \\
\hline & $\mathrm{A} 1$ fr 3 rev & AATCCTTCCCTGCGTCTTCT & Promoter & \\
\hline & A1_fr4_for & AGTCCAGAAAGGCCAAGAGC & Promoter & 340 \\
\hline & $\mathrm{A} 1$ fr4 4 rev & CAGTTTTGTAAGGGGTGAGGA & Promoter & \\
\hline & A1_fr5_for & AGGGTGGGTCTGTTTGCTCT & Promoter & 403 \\
\hline & A1 longR/fr5 rev & AAATGCCTATGACCAGATTTAGTT & Promoter & \\
\hline
\end{tabular}

\section{Analysis of GSTA1 polymorphisms}

Mutation screening of the GSTA1 gene located on chromosome 6p12.1, including the detection of $G S T A 1 * A / * B$ alleles, was conducted by analyzing the promoter nucleotide sequence (from bp -1561 in the promoter to bp 109 in the first exon) using Sanger sequencing. The strategy to determine the selected region in the GSTA1 gene without the pseudogene and homologous sequences was achieved using a 2-step PCR with specific primers (Table 1) (Bredschneider et al., 2002). The first round of PCR amplified the 1.67-kb promoter fragment and was performed in a total volume of $25 \mu \mathrm{L}$ with $80 \mathrm{ng}$ DNA, $2.5 \mu \mathrm{L}$ 10X PCR buffer containing $\mathrm{MgCl}_{2}$ (DyNAzyme EXT Optimized Buffer; Thermo Scientific, Waltham, MA, USA), $2.5 \mu \mathrm{L}$ dNTP mix ( $2.5 \mathrm{mM}$ of each dNTP), $0.5 \mu \mathrm{M}$ primers, and $0.3 \mathrm{U}$ DyNAzyme EXT DNA Polymerase (Thermo Scientific). The program started with an initial denaturation at $94^{\circ} \mathrm{C}$ for 2 min and then 35 cycles as follows: $15 \mathrm{~s}$ at $94^{\circ} \mathrm{C}, 30 \mathrm{~s}$ at $60^{\circ} \mathrm{C}, 2 \mathrm{~min}$ at $72^{\circ} \mathrm{C}$, and a final elongation for $7 \mathrm{~min}$ at $72^{\circ} \mathrm{C}$. Next, $1 \mu \mathrm{L}$ PCR product from the first round and $0.2 \mu \mathrm{M}$ second-step primers were used for nested PCR, where 5 fragments covering the $1.67-\mathrm{kb}$ promoter region were amplified in separated reactions. After purification of the final amplicons using the QIAquick $^{\mathrm{TM}}$ PCR purification kit (Qiagen), sequencing reactions were performed. All PCRs were carried out in an Applied Biosystems 2720 Thermal Cycler (Applied Biosystems). Sequencing of all 5 fragments covering the promoter region of 160 subjects was performed bidirectionally on the MegaBACE ${ }^{\mathrm{TM}} 1000$ DNA Analysis System (Amersham Biosciences, Buckinghamshire, UK) using DYEnamic ${ }^{\mathrm{TM}}$ ET Dye Terminator technology. 


\section{Statistical analysis}

The agreement of genotype distribution of the GSTP1 and GSTA1 polymorphisms with Hardy-Weinberg equilibrium was evaluated using the calculator available on the following website: http://ihg.gsf.de/cgi-bin/hw/hwa2.pl. Based on the threshold $\mathrm{P}$ value $(\mathrm{P}>0.001)$, the SNPs were classified for haplotype analysis using the Haploview v.3.11 software (Khrunin et al., 2009).

\section{RESULTS}

A total of 160 subjects from the Polish population were genotyped for polymorphisms (c.313A $>\mathrm{G}$, rs1695 and c.341C $>\mathrm{T}, \mathrm{rs} 1138272$ ) in the GSTP1 gene using pyrosequencing and screened for genetic variants in the $1.67-\mathrm{kb}$ promoter region of the GSTA1 gene using Sanger sequencing.

In GSTP1, we found both single nucleotide changes, c.313A $>\mathrm{G}$ and c.341C $>\mathrm{T}$ in both heterozygous and homozygous status with variant allele frequencies of 34.7 and $10.9 \%$, respectively (Table 2). Our haplotype analysis confirmed strong linkage disequilibrium $\left(\mathrm{D}^{\prime}=1\right)$ between these SNPs (Figure 1), and showed that alleles GSTP1*A (c.313A, c.341C), ${ }^{*} B\left(\right.$ c.313G, c.341C), and ${ }^{*} C$ (c.313G, c.341T) were observed with frequencies of $65.3,23.8$, and $10.9 \%$, respectively (Table 3 ).

Table 2. Frequencies of GSTP1 and GSTA1 gene variants in 160 individuals of the Polish population.

\begin{tabular}{|c|c|c|c|c|c|c|}
\hline \multirow[t]{2}{*}{ Gene } & \multirow[t]{2}{*}{ SNP } & \multicolumn{3}{|c|}{ Genotypes } & \multirow[t]{2}{*}{ Variant allele frequency (\%) } & \multirow[t]{2}{*}{$\mathrm{HWE}^{\mathrm{a}}$ (P value) } \\
\hline & & Homozygous wild type & Heterozygous & Homozygous mutant & & \\
\hline \multirow[t]{2}{*}{ GSTP1 } & A313G & $67(41.8 \%)$ & $75(46.8 \%)$ & $18(11.4 \%)$ & 34.7 & 0.66 \\
\hline & C341T & $129(80.6 \%)$ & $27(16.9 \%)$ & $4(2.5 \%)$ & 10.9 & 0.09 \\
\hline \multirow[t]{8}{*}{ GSTA1 } & G-52A & $54(33.7 \%)$ & $74(46.3 \%)$ & $32(20 \%)$ & 43.1 & 0.47 \\
\hline & C-69T & $54(33.7 \%)$ & $74(46.3 \%)$ & $32(20 \%)$ & 43.1 & 0.47 \\
\hline & A-513G & $148(92.5 \%)$ & $8(5 \%)$ & $4(2.5 \%)$ & 5.0 & $<0.001$ \\
\hline & $\mathrm{T}-567 \mathrm{G}$ & $54(33.7 \%)$ & $74(46.3 \%)$ & $32(20 \%)$ & 43.1 & 0.47 \\
\hline & G-631T & $94(58.8 \%)$ & $47(29.4 \%)$ & $19(11.8 \%)$ & 26.5 & 0.0017 \\
\hline & A-1066T & $137(85.6 \%)$ & $19(11.9 \%)$ & $4(2.5 \%)$ & 8.4 & 0.0034 \\
\hline & $\mathrm{G}-1142 \mathrm{C}$ & $53(33.1 \%)$ & $54(33.8 \%)$ & $53(33.1 \%)$ & 50.0 & $<0.001$ \\
\hline & G-1245A & $137(85.6 \%)$ & $19(11.9 \%)$ & $4(2.5 \%)$ & 8.4 & 0.0034 \\
\hline
\end{tabular}

${ }^{\mathrm{a}} \mathrm{HWE}$ (Hardy-Weinberg equilibrium, threshold $\mathrm{P}$ value is 0.001 ).

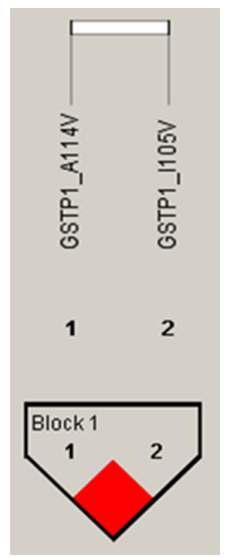

Figure 1. Associations between polymorphisms in the GSTP1 gene (pairwise linkage disequilibrium analysis). 
Table 3. Observed frequency of GSTP1 alleles among 160 Polish individuals.

\begin{tabular}{lccc}
\hline Alleles & $313 \mathrm{~A}>\mathrm{G}$ & $341 \mathrm{C}>\mathrm{T}$ & Frequency \\
\hline${ }^{*} A$ & $\mathrm{~A}$ & $\mathrm{C}$ & $65.3 \%$ \\
${ }^{*} B$ & $\mathrm{G}$ & $\mathrm{C}$ & $23.8 \%$ \\
${ }^{*} C$ & $\mathrm{G}$ & $\mathrm{T}$ & $10.9 \%$ \\
\hline
\end{tabular}

In the GSTA1 gene promoter region, a total of 8 SNPs were detected, including G52A (rs3957356), C-69T (rs3957357), A-513G (rs11964968), T-567G (rs 4715332), G-631T (rs4715333), A-1066T (rs3756983), G-1142C (rs58912740), and G-1245A (rs143523660). The genotype distributions and allele frequencies are shown in Table 2. The substitutions G-52A, C-69T, and T-567G, characterizing the 2 basic alleles GSTA1*A (-52G, -69C, -567T) and $G S T A 1 * B(-52 \mathrm{~A},-69 \mathrm{~T},-567 \mathrm{G})$, were observed with the same variant allele frequency of $43.1 \%$. All SNPs, excluding 2 at positions -513 and -1142 bp that were not in Hardy-Weinberg equilibrium, were examined in haplotype analysis. The results indicated that 4 polymorphic sites, $-52,-69,-567$, and $-631 \mathrm{bp}$, were in strong linkage disequilibrium, creating haploblock 1, as well as 2 changes, A-1066T and G-1245A, creating haploblock 2 (Figure 2). The haploblocks were inferred based on the threshold value of the pairwise linkage disequilibrium between SNPs of D' > 0.7. Finally, 4 GSTA1 alleles defined as different SNP combinations were observed in our population (Table 4).

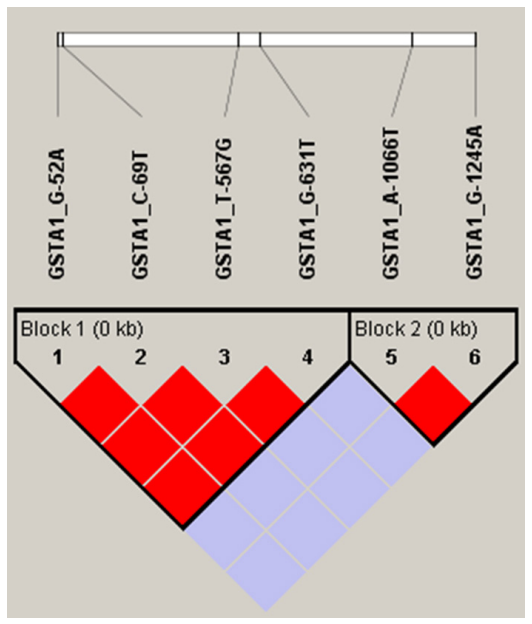

Figure 2. Associations between polymorphisms in the GSTA1 gene (pairwise linkage disequilibrium analysis).

Table 4. GSTA1 alleles defined as combinations of SNPs observed among 160 Polish individuals.

\begin{tabular}{lcccccc}
\hline Alleles & -52 & -69 & -567 & -631 & -1066 & -1245 \\
\hline$* A 1$ & $\mathrm{G}$ & $\mathrm{C}$ & $\mathrm{T}$ & $\mathrm{T}$ & $\mathrm{A}$ & $\mathrm{G}$ \\
$* A 2$ & $\mathrm{G}$ & $\mathrm{C}$ & $\mathrm{T}$ & $\mathrm{G}$ & $\mathrm{A}$ & $\mathrm{G}$ \\
$* A 3$ & $\mathrm{G}$ & $\mathrm{C}$ & $\mathrm{T}$ & $\mathrm{G}$ & $\mathrm{T}$ & $\mathrm{A}$ \\
$* B 1$ & $\mathrm{~A}$ & $\mathrm{~T}$ & $\mathrm{G}$ & $\mathrm{G}$ & $\mathrm{A}$ & $\mathrm{G}$ \\
\hline
\end{tabular}

The names *A1, $A 2, A 3, B 1$ of GSTA1 alleles were defined as combinations of SNPs found in this study: G-52A, C-69T, T-567G, G-631T, A-1066T, G-1245A. 


\section{DISCUSSION}

GST enzymes A1 and P1 and their genetic variability have been examined in numerous studies because of their crucial role in toxin and drug metabolism, drug treatment response, susceptibility of a wide range of diseases, and hepatotoxicity detection. The alleles $G S T P 1 * A,{ }^{*} B,{ }^{*} C$ and $G S T A 1 * A, * B$ are known to be responsible for variable enzyme activity for specific substrates, which may have a clinical impact, and are observed at various frequencies among different populations and ethnic groups (Allan et al., 2001; Morel et al., 2002). We identified and evaluated the distribution of the polymorphisms characterizing these alleles in a Polish population.

Our results showed that the polymorphisms c.313A $>\mathrm{G}$ (p.Ile105Val) and c.341C $>\mathrm{T}$ (p.Ala114Val) in the GSTP1 gene are present in the Polish population at allele frequencies of 34.7 and $10.9 \%$, respectively, confirming the results obtained for Caucasians in the NCBI database: $33-50 \%$ for Val105 and 6-12\% for Val114. Moreover, we found through haplotype analysis that both nucleotide substitutions are always linked, creating the alleles GSTP1*A (c.313A, c.341C), ${ }^{*} B$ (c.313G, c.341C), and ${ }^{*} C$ (c.313G, c.341T) according to a study conducted by Ali-Osman et al. (1997), and were found in the Polish population with frequencies of $65.3,23.8$, and $10.9 \%$. The genotype distribution as well as the frequency of the Ile105Val polymorphism observed in this study did not largely differ from those reported in another Central European population, the Czechs; the variant allele in this group has a reported frequency of $34.4 \%$, and the heterozygote genotype was found to be associated with a decreased risk of colorectal cancer (Hezova et al., 2012). In contrast to our results, the frequency of this allele was higher in a Serbian population, reaching 37.6\% (Suvakov et al., 2013). The genotype Ile105Ile frequency observed in our study $(41.8 \%)$ was similar to that determined by Vichi et al. (2012) in a healthy Italian population (42\%), where this genotype was found to be associated with a higher risk of endometriosis (frequency in cases, 48.6\%). Polymorphism I105V was also studied by Burim et al. (2004) in the Brazilian population in association with cirrhosis or pancreatitis in alcoholics. A possible association was observed between the Val105Val genotype and increased susceptibility to these diseases in alcoholics $(7.3 \%$ in healthy Brazilian vs $28.6 \%$ in pancreatitis cases) (Burim et al., 2004). Kaymak et al. (2008) found that heterozygous (GSTP1 I105V) individuals in a Turkish population undergoing sevoflurane anesthesia showed an increased level of serum $\alpha$-GST enzyme within $24 \mathrm{~h}$ after anesthesia. International studies have indicated that the Val105 allele is more common in African-Americans (42\%), but less common among Chinese (22\%), Taiwanese (18\%), and Japanese (14\%) populations compared to European-Americans (33\%), while allele Val114 is less often observed in African-Americans (5\%) than in European-Americans (9\%) (Watson et al., 1998; Zhong et al., 2006).

The second aim of the present study was to determine the distribution of alleles GSTA $1 * A / * B$ in the Polish population based on 3 crucial polymorphisms at positions $-52,-69$, and -567 and to search for other SNPs in the promoter region, which may be linked to these alleles and contribute to the inter-individual variability of GSTA1 expression. In the 1.67-kb promoter region (with exon 1 fragment) of the human GSTA1 gene, we identified 8 SNPs, including G-52A, C-69T, A-513G, T-567G, G-631T, A-1066T, G-1142C, and G-1245A, confirming the results of Bredschneider et al. (2002) in Caucasians, except for the SNP that was only observed in our study at site -1245 . The frequency of the $G S T A 1 * B$ allele containing 3 linked basic variants affecting gene expression $(-52 \mathrm{~A},-69 \mathrm{~T},-567 \mathrm{G})$ observed in our study among 160 individuals (43.1\%) was slightly lower than that observed by Bredschneider et al. 
(2002) among 48 subjects (47.9\%), but showed some similarities, including genotype distribution, to the data of global studies in the Caucasian population (38-50\%) (Coles et al., 2001; Spalletta et al., 2012; Suvakov et al., 2013). However, in African-American, Japanese, and Chinese subjects, the allele frequency was much lower, at 26, 16, and $12.9 \%$, respectively (Coles et al., 2001; Matsuno et al., 2004; Ping et al., 2006). The lower transcriptional activity of the $G S T A 1^{*} B$ allele compared to $G S T A 1^{*} A$ is mainly responsible for a base substitution at position -52, altering the binding process of transcription factor Sp1 (Morel et al., 2002). Another observation from our study, confirming the results of previous research, was that the polymorphism at position -631 was linked to the alleles GSTA1*A (-631T/G) and *B (-631G) and associated with lower hepatic expression (Coles et al., 2001; Bredschneider et al., 2002). Moreover, based on our haplotype analysis, we observed a remarkable association between SNPs A-1066T and G-1245A, and both were observed at a frequency of 8.4\% (Figure 2). The 4 alleles containing various combinations of SNPs were in Hardy-Weinberg equilibrium and identified in all 160 subjects of the Polish population (Table 4). However, the single nucleotide substitutions A-513G and G-1142C were not included in the haplotype analysis, but were observed at frequencies of 5 and $50 \%$, respectively, corresponding to the data in the literature. In contrast to our results, a study by Guy et al. (2004) indicated the presence of other changes and combinations in the GSTA1 promoter region, and showed different haplotypes such as GSTA ${ }^{*} A,{ }^{*} C,{ }^{*} D$, and ${ }^{*} E$ based on the SNPs G-52A, C-69T, G-115A, and A-513G.

This is the first study examining the $G S T A 1 * A / * B$ allele distributions in the Polish population. We not only identified the 3 well-known linked SNPs at positions -52 , -69 , and -567 , but also identified other polymorphisms associated with these alleles, revealing haplotypes of the GSTA1 gene. Determining the prevalence of the $G S T A 1 * A / * B$ alleles in various populations and ethnic groups is a valuable step for clinical and medical applications because the activity of the GSTA1 enzyme is involved in a wide range of important processes in the human body. Furthermore, our results regarding the GSTP1 gene agree with those of previous studies performed on Caucasians and allowed for the determination of the GSTP $1 * A,{ }^{*} B$, and ${ }^{*} C$ allele frequencies in Polish individuals.

\section{ACKNOWLEDGMENTS}

Research supported by the Polish Ministry of Science and Higher Education (grant \#N N401 037838). Oliwia Zakerska-Banaszak holds a scholarship from the European Regional Development Found - ERDF and the European Fund for Innovative Economy and Foundation for Polish Science. She also holds a scholarship within the project "Scholarship support for Ph.D. students specializing in majors strategic for Wielkopolska's development", Submeasure 8.2.2 Human Capital Operational Programme, co-financed by European Union under the European Social Fund.

\section{REFERENCES}

Ali-Osman F, Akande O, Antoun G, Mao JX, et al. (1997). Molecular cloning, characterization and expression in Escherichia coli of full length cDNAs of three human glutathione S-transferase Pi gene variants: evidence for differential catalytic activity of the encoded proteins. J. Biol. Chem. 272: 10004-10012.

Allan JM, Wild CP, Rollinson S, Willett EV, et al. (2001). Polymorphism in glutathione S-transferase P1 is associated with susceptibility to chemotherapy-induced leukemia. Proc. Natl. Acad. Sci. U. S. A. 98: 11592-11597.

Bai YL, Zhou B, Jing XY, Zhang B, et al. (2012). Predictive role of GSTs on the prognosis of breast cancer patients with 
neoadjuvant chemotherapy. Asian Pac. J. Cancer Prev. 13: 5019-5022.

Beyaz SG, Yelken B and Kanbak G (2011). The effects of N-acetylcysteine on hepatic function during isoflurane anaesthesia for laparoscopic surgery patients. Indian J. Anaesth. 55: 567-572.

Board PG, Webb GC and Coggan M (1989). Isolation of a cDNA clone and localization of the human glutathione S-transferase 3 genes to chromosome bands 11q13 and 12q13-14. Ann. Hum. Genet. 53: 205-213.

Bredschneider M, Klein K, Mürdter TE, Marx C, et al. (2002). Genetic polymorphisms of glutathione S-transferase A1, the major glutathione S-transferase in human liver: consequences for enzyme expression and busulfan conjugation. Clin. Pharmacol. Ther. 71: 479-487.

Burim RV, Canalle R, Martinelli Ade L and Takahashi CS (2004). Polymorphisms in glutathione S-transferases GSTM1, GSTT1 and GSTP1 and cytochromes P450 CYP2E1 and CYP1A1 and susceptibility to cirrhosis or pancreatitis in alcoholics. Mutagenesis 19: 291-298.

Canto P, Canto-Cetina T, Juárez-Velázquez R, Rosas-Vargas H, et al. (2008). Methylenetetrahydrofolate reductase C677T and glutathione S-transferase P1 A313G are associated with a reduced risk of preeclampsia in Maya-Mestizo women. Hypertens. Res. 31: 1015-1019.

Coles BF, Morel F, Rauch C, Huber WW, et al. (2001). Effect of polymorphism in the human glutathione S-transferase A1 promoter on hepatic GSTA1 and GSTA2 expression. Pharmacogenetics 11: 663-669.

Eger EI 2nd, Koblin DD, Bowland T, Ionescu P, et al. (1997). Nephrotoxicity of sevoflurane versus desflurane anesthesia in volunteers. Anesth. Analg. 84: 160-168.

Guy CA, Hoogendoorn B, Smith SK, Coleman S, et al. (2004). Promoter polymorphisms in glutathione-S-transferase genes affect transcription. Pharmacogenetics 14: 45-51.

Harries LW, Stubbins MJ, Forman D, Howard GC, et al. (1997). Identification of genetic polymorphisms at the glutathione S-transferase Pi locus and association with susceptibility to bladder, testicular and prostate cancer. Carcinogenesis 18: 641-644.

Hayes JD and Pulford DJ (1995). The glutathione S-transferase supergene family: regulation of GST and the contribution of the isoenzymes to cancer chemoprotection and drug resistance. Crit. Rev. Biochem. Mol. Biol. 30: 445-600.

Hayes JD and Strange RC (2000). Glutathione S-transferase polymorphisms and their biological consequences. Pharmacology 61: 154-166.

Hezova R, Bienertova-Vasku J, Sachlova M, Brezkova V, et al. (2012). Common polymorphisms in GSTM1, GSTT1, GSTP1, GSTA1 and susceptibility to colorectal cancer in the Central European population. Eur. J. Med. Res. 17: 17.

Kaymak C, Karahalil B, Ozcan NN and Oztuna D (2008). Association between GSTP1 gene polymorphism and serum alpha-GST concentrations undergoing sevoflurane anaesthesia. Eur. J. Anaesthesiol. 25: 193-199.

Khrunin A, Mihailov E, Nikopensius T, Krjutskov K, et al. (2009). Analysis of allele and haplotype diversity across 25 genomic regions in three Eastern European populations. Hum. Hered. 68: 35-44.

Knapen MF, Peters WH, Mulder TP and Steegers EA (2000). A marker for hepatocellular damage. Lancet 355: 1463-1464.

Krajka-Kuźniak V (2007). Induction of phase II enzymes as a strategy in the chemoprevention of cancer and other degenerative diseases. Postepy Hig. Med. Dosw. 61: 627-638.

Matsuno K, Kubota T, Matsukura Y, Ishikawa H, et al. (2004). Genetic analysis of glutathione S-transferase A1 and T1 polymorphisms in a Japanese population. Clin. Chem. Lab. Med. 42: 560-562.

Morel F, Rauch C, Coles B, Le Ferrec E, et al. (2002). The human glutathione transferase alpha locus: genomic organization of the gene cluster and functional characterization of the genetic polymorphism in the hGSTA1 promoter. Pharmacogenetics 12: 277-286.

Moscow JA, Fairchild CR, Madden MJ, Ransom DT, et al. (1989). Expression of anionic glutathione-S-transferase and P-glycoprotein genes in human tissues and tumors. Cancer Res. 49: 1422-1428.

Oakley AJ (2005). Glutathione transferases: new functions. Curr. Opin. Struct. Biol. 15: 716-723.

Ping J, Wang H, Huang M and Liu ZS (2006). Genetic analysis of glutathione S-transferase A1 polymorphism in the Chinese population and the influence of genotype on enzymatic properties. Toxicol. Sci. 89: 438-443.

Ray DC, Beckett GJ, Hayes JD and Drummond GB (1989a). Effect of nicardipine infusion on the release of glutathione S-transferase following halothane anaesthesia. Br. J. Anaesth. 62: 553-559.

Ray DC, Howie AF, Beckett GJ and Drummond GB (1989b). Preoperative cimetidine does not prevent subclinical halothane hepatotoxicity in man. Br. J. Anaesth. 63: 531-535.

Rowe JD, Nieves E and Listowsky I (1997). Subunit diversity and tissue distribution of human glutathione S-transferases: interpretations based on electrospray ionization-MS and peptide sequence-specific antisera. Biochem. J. 325: 481-486.

Spalletta G, Piras F, Gravina P, Bello ML, et al. (2012). Glutathione S-transferase alpha 1 risk polymorphism and increased bilateral thalamus mean diffusivity in schizophrenia. Psychiatry Res. 203: 180-183.

Suvakov S, Damjanovic T, Stefanovic A, Pekmezovic T, et al. (2013). Glutathione S-transferase A1, M1, P1 and T1 null or low-activity genotypes are associated with enhanced oxidative damage among haemodialysis patients. Nephrol. Dial. Transplant. 28: 202-212. 
Sweeney C, Coles BF, Nowell S, Lang NP, et al. (2002). Novel markers of susceptibility to carcinogens in diet: associations with colorectal cancer. Toxicology 181: 83-87.

Tetlow N, Liu D and Board P (2001). Polymorphism of human Alpha class glutathione transferases. Pharmacogenetics 11: 609-617.

van Ommen B, Bogaards JJ, Peters WH, Blaauboer B, et al. (1990). Quantification of human hepatic glutathione S-transferases. Biochem. J. 269: 609-613.

Vichi S, Medda E, Ingelido AM, Ferro A, et al. (2012). Glutathione transferase polymorphisms and risk of endometriosis associated with polychlorinated biphenyls exposure in Italian women: a gene-environment interaction. Fertil. Steril. 97: 1143-1151.

Watson MA, Stewart RK, Smith GB, Massey TE, et al. (1998). Human glutathione S-transferase P1 polymorphisms: relationship to lung tissue enzyme activity and population frequency distribution. Carcinogenesis 19: 275-280.

Wu B and Dong D (2012). Human cytosolic glutathione transferases: structure, function, and drug discovery. Trends Pharmacol. Sci. 33: 656-668.

Yousif MA, Khafagy HF, El-Shanawani FM, El-Sabae HH, et al. (2009). Hepatocellular integrity during sevoflurane anesthesia with induced hypotension. J. Egypt. Soc. Parasitol. 39: 641-651.

Zhong H, Feng Y, Zheng GX, Liang Y, et al. (2013). A meta-analysis of the association between glutathione S-transferase P1 gene polymorphism and the risk of adenocarcinomas of lung cancer. Cancer Biomark. 13: 29-35.

Zhong SL, Zhou SF, Chen X, Chan SY, et al. (2006). Relationship between genotype and enzyme activity of glutathione S-transferases M1 and P1 in Chinese. Eur. J. Pharm. Sci. 28: 77-85. 